DESIGNING THE DREAM IN

POSTWAR AMERICAN SUBURBIA

A Thesis
presented to
the Faculty of the Graduate School
at the University of Missouri-Columbia
In Partial Fulfillment
of the Requirements for the Degree
Master of Science
by
ASHTON OLTMANNS
Dr. Benyamin Schwarz, Thesis Supervisor
July 2014


The undersigned, appointed by the dean of the Graduate School, have examined the thesis entitled

\section{DESIGNING THE DREAM IN POSTWAR AMERICAN SUBURBIA}

presented by Ashton Oltmanns,

a candidate for the degree of Master of Science,

and hereby certify that, in their opinion, it is worthy of acceptance.

Professor Benyamin Schwarz

Professor Ruth Tofle

Professor Kristen Schwain 


\section{Acknowledgements}

This master's thesis was created with the help and guidance of so many that have helped to shape my education, career path, and focus of study; all of which to whom I owe a great deal of gratitude. Without their continued support this body of work would not be possible and my future path would not nearly look as bright.

Dr. Schwarz has been my advisor since I began my studies six years ago at the Undergraduate level and has seen my progression both academically and professionally. Now that I work towards an eventual Ph.D, it is to him that I owe so much to. Inspiring students to continue to accept nothing than the very best and reach my fullest potential is a gift that he bestows upon all. You always push your students to achieve their greatest potential and such a mentality is reflected in your own quality of work as well. Moving forward with my studies, it is my hope that I may be able to provide the same quality of education, advising, and facilitation of growth with my own students.

Dr. Tofle has been a great leader and has provided me with the opportunities to blossom as an educator and grow my depth of experiences in the design education sector. Your unfailing optimism is always a light that you give off seemingly at all times. As your student and peer I will always value your perspective on facilitating student growth.

Dr. Schwain's course on visual studies was the catalyst to which subsequently inspired my master's study and this project itself. Understanding the intense meaning behind seemingly ordinary objects and finding the art in architecture was a refreshing 
perspective on how we view our material world. Your work has inspired my own and I credit you to planting the seed of interest in the field of archival research.

Finally, I would like to thank my family and friends for keeping me grounded and providing much needed support through the process of creating this thesis. Having a rock to hold on to while traversing the rocky waters of research and writing was more helpful than words could express. 


\section{Table of Contents}

Acknowledgements............................................................................... ii

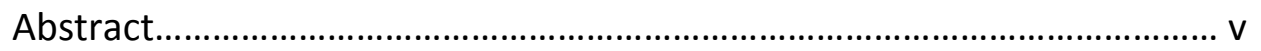

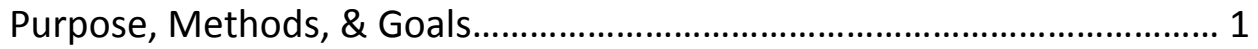

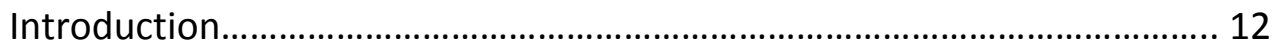

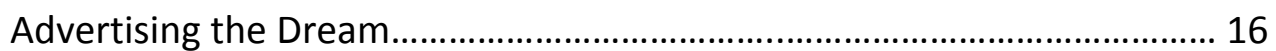

Dreamy Expectations \& the Reality of the Architect.................................. 19

Self and Suburbia: American Dream via Dream House? ............................ 24

Interpreting Form, Function and Style................................................ 27

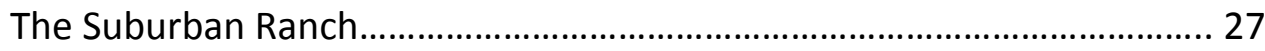

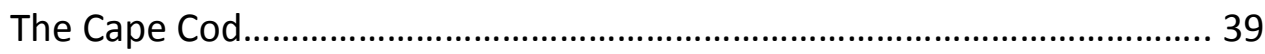

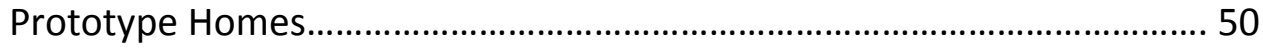

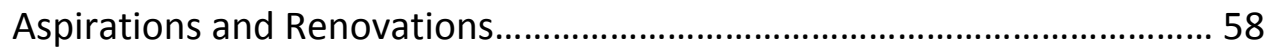

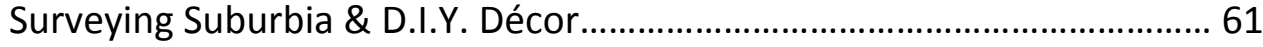

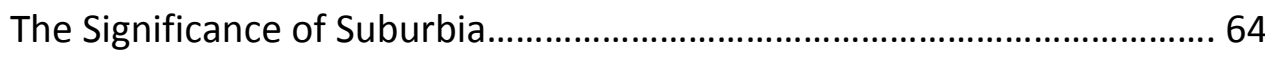

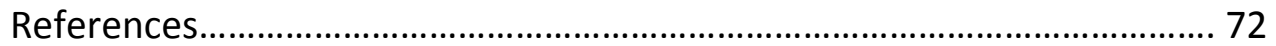




\section{Abstract}

"Everytime I run across an article relating how archaeologists are excavating and interpreting a new dig, I can't help but wonder what would happen should our civilization be abruptly extinguished" - (Nancy Stahl, 1975).

The American suburban landscape is intrinsically intertwined with our national identity. As a symbol of expansion, safety, success and the "American Dream", our suburban landscape has provided us with a housing system that is affordable in its anonymity from "sea to shining sea". While often the topic of debate on its sociocultural successes and pitfalls, the images of suburbia are forever marked on our young nation's history. Understanding this history, however, is a multi-dimensional task that forces us to examine our suburban landscape as a piece of our unique visual and material culture. As quoted above, Nancy Stahl's poignant reflection asks of us what does our modern artifacts reveal about ourselves, and perhaps, our values and lifestyles. The intention of this research is not to critique, but rather, historically document the contents of our suburban material culture, and understand how we translated our intangible societal norms into palpable architectural design. Clyde Kluckhohn, an anthropologist, describes culture as "a set of looking glasses that strongly influence what we see taking place before us" (1949). By examining suburban home design and its importance in media as a piece of visual culture, the goal of the study is to assess cultural desires and commodification of the post war residential landscape. 


\section{Purpose, Methods \& Goals}

"Contemporary is usually associated with large glass areas. But it certainly is not a white cube, not a flat roof, not corner windows, but just an unself conscious attempt to design the best house to live in."

- (Walter Adams, "What America Wants to Build", Quoted in "The American Family Home”, Clark 1986)

For centuries, man has looked to the domestic landscape as a window into the culture of civilizations past. Providing for researchers a way to examine the daily activities of those who inhabited the structure, a house could also be telling of an entire community's way of life, including every day rituals, social and governmental hierarchy, cultural customs, and architectural construction systems. More so than any other structure, the suburban domicile is a way of examining both micro and macro systems, whether it be far and/or recent past.

Suburbia is, however, a place full of "complexities and contradictions" as one post-modernist architectural critic would term. The suburban landscape is the symbol of status, success, stability and security, while at the same time the subject of blame for egregious modern consumption, white-collar crime, and the death of self-sufficiency. While on one hand we celebrate the current suburbia as prompting middle class mobility, we strike the other hand that promotes a housing model that is built on quantity rather than quality. Suburbia is a topic that celebrates the American dream, while at the same time, airing grievances of the manufactured manifestation of home.

To date, there have been a variety of studies done detailing the history of suburbia. Such research often looks at the communities themselves and the transportation and commercialization changes that they have caused. However, such 
studies are limited in their scope when regarding a study of the homes themselves as a physical form and as a piece of a media objectification documented by an increasingly visual and media centric culture. My historical review intends to objectify the suburban home as a cultural marker and as a piece of material culture through popular housing magazines and editorials. Additionally, this study intends to identify the "pieces" of the residential puzzle that exemplify the cultural phenomena within the intended decade of 1945-55 (i.e., floor plan layout, size, exterior façade arrangement, and design features). By looking at these pieces of American historical, visual and suburban culture through the lens of the media eye, we not only are able to identify the idealistic goals of the post war American public, but the true sense of what the American Dream was during that era.

In many ways, we term such a mentality an American "Dream" rather than an American "Reality" because there exists an air of idealism, naivety and fantasy-esque expectations. Such a lifestyle and materialistic expectations are created through repetitive socio-cultural constructs that are reinforced through the picture perfect imagery in popular media. This phenomena continues to hold true today, as we migrate towards an every increasing visual culture where the expectations we seek of ourselves and our peers are reinforced through magazines, movies, and television. At the particular time to which this research will examine, the influence of imagery in creating new jobs, new housing, and a seemingly unlimited prospect for growth was increasingly widespread and important in shaping the way in which the United States would prosper after the war. 
In the post-war era, imagery of family, prosperity, and peace-time harmony that were propagated through our media and government agencies were not entirely false, however. After the turn of the century, the housing market, along with any new construction and economic growth, went through a kind of roller coaster of highs and lows, taking with it the hope and expectations of a nation. Although rising at the beginning of the 1900 's, the building boom for single family housing in the United States slowed down somewhat during WW1, rose again slightly in the 1920's, but came to a grinding halt during the Great Depression (Clark 1986). In the following decade, "the housing market remained weak...middle-class Americans who were fortunate enough to have a job tended to spend their limited funs on small remodeling projects" $(1986,193)$. While slow, any burgeoning hopes of a rising housing market were once again thwarted in the early 1940's with the outbreak of World War II which sucked building materials and rerouted manufacturing jobs. By the end of the war, however, the same middleclass Americans who were forced to limit their expectations and standard of living during the war, began have new hope again $(1986,192)$. For many Americans, "the postwar housing market, they believed, would open up vast new opportunities to choose the home of their dreams" (Clark, 1986, 193). Capitalizing on this upswing mentality was paramount to the construction and housing industry, the American Economy, and the American government in order to see American reach its full potential.

Moreover, magazines such as Time, Life, Better Homes and Gardens Magazine, and Good Housekeeping not only propagated popular housing styles and lifestyle 
expectations, they also acted as a forum for very powerful critique and debate over the various forced impacting the growing housing market. While on one had there exists a kind of fantasy-eque lifestyle on the glossy magazine pages of model homes and designer interiors, these publications also provided a unique and effective means to which we can see an inner struggle over what shape our suburban landscape was taking. Although specific instances will be discussed later in this research, the magazines arguably one of the most controversial, yet effective means to which we can examine the information, right or wrong, given to the masses. While on one hand the magazines themselves act as a perfect picture window into which we see distorted views of what the new America "should be", we also see at times a very honest look into how those who were building suburbia interacted and communicated with its residents. Moreover, while on one hand we have imagery created through idealism, stereotypes, and fantasy, we are also able to discern socio-cultural expectations, architectural trends, and an honest look at what information was given to influence the average American homeowner.

In one such instance, a closer inspection of the suburban housing developments via survey in the magazine Better Homes and Gardens would prove that neither the defenders nor the critics of suburbia were truly accurate in their assumptions of suburbia (Clark, 1986, 227). By polling their readers in a 1955 survey, the true rationale for purchasing suburban homes revealed to be more complex than anyone had truly anticipated. According to the survey conducted, two kinds of families bough houses in the years 1949 and 1950: 
"Nearly half of the home buyers were veterans of World War II. They were a younger group, with a median age of thirty-five, who had young children and had run out of space in their apartments. Dissatisfaction with the rental market, the desire for more independence and privacy, the ease of obtaining loans, and the belief that home ownership was a good investment prompted this younger group to buy its first house.... When asked why they had moved, the 'need for more space,' 'comfort and rommieness for family members in a new house,' and 'privacy and freedom of action in owner home' were the reasons most often given. Contrary to the utopian visions put forth by architects and home magazines, the inadequacies of their previous housing were more important precipitants of the decision to buy than the emphasis on convenience or the lure of new designs. The other largest group of buyers in the 1949-50 housing market was made up of older families whose media age was forty-five. Many of these families moved from a previously owned house because the space was inadequate and their family needs had changed. Others preferred the quiet of being further from the central city or moved because of a change in job... Together with the younger families of veterans, these home buyers helped fuel a massive exodus from the cities that was to increase suburban growth by more than 50 percent during the decade" -(As quoted in Clark, 1986, 227-28)

While the magazines admittedly glamorize housing trends and create almost a "utopian" imagery of suburbia, they did take a very useful and notable advantage of 
their wide reaching reading demographic to provide a unique, yet accurate, account for the popularity of suburbia itself and the preferences of its owners. Using such magazines as a looking glass to which we can examine this unique era in American housing, provides a dynamic insight into the trends, influencing forces, and sociocultural factors that shape our suburban landscape. While on face value, using magazines to examine both the products of suburban housing and suburbanites themselves seems like a skewed generalization of what was truly occurring during the era, when we take into account both the massive reach of influence these magazines had and their ability to use and reflect cultural preferences, perhaps the print is not as skewed as one would think.

\section{Methods}

To execute the analysis of the suburbia, the magazine Better Homes and Gardens, House Beautiful, Life and Time were gathered and examined for their content regarding house and home during the 10 years immediately following the conclusion of World War II. Articles, images and advertisements were all examined and subsequently categorized by their content and choice of suburban architectural subject. While numerous home styles were included in the magazines, the specific home styles that are examined were chosen due to their sheer volume of coverage/inclusion in the magazines the availability of home plans for purchase and construction. Rather than focus on unique examples of house designs that were highlighted as "exemplary" or "opulent", the designs that were analyzed in the following review reflect the "average" 
or "ordinary" in order to capture the dichotomy between expectations and execution in suburban housing.

Trending house features due to popularity and stylistic preferences are highlighted and detailed in terms of their architectural significance, technical evidence, and defining qualities. Examples of examination factors include, but are not limited to, size, color, geometry, construction, location, organization, hierarchy and quantity. Scope and type of house "features" are identified as any form of decoration on the interior or exterior, shape or size of house form, interior specifications, room use type, and architectural design of significant style identifiers. Such stagnant architectural features are then counterbalanced with social and cultural dynamic factors in terms of how it would influence the way its inhabitants would use the space, view the space, and interact with others while using the house. Architectural features also are regarded and reviewed at a macro level through the means by which housing construction methods subsequently influenced the suburban construction market and home builder methodology. Moreover, socio-cultural factors are also related back to the magazines to which they arise from through how they are advertised and marketed to the end consumer. Any subsequent indicators of gender roles, family relationships, and expectations of creating a suburban home are finally reflected in the ambiguous yet wildly influential creation of the "American Dream".

Paramount to this analysis is the understanding of the following terminology, both in how they will be used in this review and how they are used in the media subject to influence the end consumer. 


\section{Home vs. House}

The term "home" and "house" are often used interchangeable in the field of architecture, but it is important to understand the distinct difference between these two terms in the context of this study. For the purpose of historical examination, the "house" will be examined as an object of material culture. The "house" is a structurally independent space that is examined for its composition of interior spaces, exterior decoration and geometry, and materials. On the other hand, "home" will be used for its socio-cultural construct as an independent place that holds specific meaning, memory, and tradition in a subjective sense. Thus, "Home" as a term for this study is interpreted as a construct of the American Dream and holds importance as a foundation of culture and society within the post war period.

However, both terms are just as loaded with meaning within them as they are between them. On a more pragmatic level, the definition of home is a multilayered model. Vikko (1996) states: "On one hand, the home is a residence and thereby a source of an environment for daily routines. As a resident, the home creates a frame for how (we) manage everyday tasks... On the other hand, we can see the homes as being charged with symbolic meaning: the home refers to a mental and social well-being, the home is a totality of meaning-charged cavity and the home is an experienced space". For the purposes of this work, the image of the home will be used as a first-place within which one defines the most private sector of space.

On the other hand, a description of physical identifiers of a house to be examined within this study becomes problematic when describing due to the "mixing 
bowl" effect that occurs within the United States both culturally and geographically (or even through national media as discussed previously). For example: Why in the United States do we see Cape Cod homes in the Mid-West if topography or local culture were factors? Why would a home have an open air plan with vaulted ceilings in both subtropical and sub-artic regions in the United States if climate was truly a factor? Thus, this research will look towards the work of Altman \& Chemers (1980) as a working classification for examining homes so that the appropriate research can be conducted: "permanent/temporary, differentiated/homogenous/ and communal/noncommunal" (Altman \& Chemers, 1980). This distinction in particular will be increasingly important when looking at post WWII homes and identifying architectural features of home design. Due to the variety and availability of tract homes across the nation, identifying housing "types" can be seen as largely independent from regional or climate influences. The recognition of a national prototype for housing was beginning to emerge at a macro scale, and will be the primary subject for further research.

\section{Material Culture}

Finally, it is important to address the working definition material culture in relation to mass consumption, within which we find the objectivity of home. Miller (1987) outlines the importance of material culture in a society of mass consumption, arguing that culture the result of the active use people make of goods as artifacts in their daily lives. He continues by arguing that the understanding of consumption is critical to the analysis of industrialized societies being that it serves as an indicator of personal and social relationships to material culture. However, it is not within this 
explanation that I look to my definition of material culture. Rather, I would like to look towards the application of material culture to define both its use and its significance. In a working definition for the modern role of archaeology when exploring material culture, Rathje (1979) states: “[modern] archaeology [has] a single defining characteristic: a focus on the interaction between material culture and human behavior and ideas, regardless of time or space". This telling definition shows us that material culture has strong relationships to both human behavior and our own cultural imprint we leave when our society ceases to exist. The use of material culture for this research provides a framework for breaking down home design into identifiable pieces that describe cultural trends and needs (i.e. organization of plan, façade arrangement, and size).

Hudson (1984) makes the argument that modern material culture now allows anthropology to be a current form of archeology. By examining homes as a reflection of a material to be consumed, a wealth of research would be provided into how our trend towards consumption has changed our own perception of home and how it can be used as a cultural identifier, thus providing an interesting platform to answer my research question. In the era to be examined, the perpetuation of the home in a mass scale meant that quantity and affordability were the most desirable traits.

Goals

The goals of this study promote the concepts of material culture and architectural design as they relate historically to the suburban housing boom in the five years following the conclusion of World War II. The goals directly relate to the research 
questions and inform the design of the following exploration. The goals as presented here propose an understanding and justification of the concepts.

1. To understand the relationship between the home and the material culture in the context to which it signifies.

2. To understand the popular housing features of those designed in suburban neighborhoods during the decade under review.

3. To understand the media and advertising methods to which "trending" residential home features were propagated during the years under review.

4. To understand which suburban home features work as signifiers for larger cultural values.

5. To understand the evolution of housing trends and the factors which influence it. 


\section{Introduction: Setting the Suburban Stage}

Figure 1:

Postwar home planning advertisement showcasing a loving couple gazing through a catalogue of home options, dreaming of what a future home could create for them. Better Homes and Gardens Magazine, May 1946, Pg.

77
The end of World War II signaled the beginning of a new America.

Both figuratively and quite literally, the decades following the allies victory overseas signaled the creation of a new American identity predicated on economic and peacetime cultural prosperity. Manufacturing that had shifted to wartime weapons and supply during the war, was now back at work stimulating the economy and resuming construction endeavors that would

redefine the urban periphery. Men and women hard at work defending their country were now returning home reimaging their country, and perhaps, what it meant to be American entirely. By the end of 1945 , there were "3,600,000 families lacking homes...[and] the return of thirteen million servicemen and women thus created a massive housing shortage overnight" (Clark, 1986, 196).

The United States as a nation had changed, both on a world stage and at home. As a new "world power", American influence on a global scale was increasing and the stimulus from such a status had ramifications at home. By the end of the war, America had already began the process of disengaging ourselves from our industrialized past, “manual work was becoming less valued...office buildings displaced factories as the era's dominant urban image; consumption surpassed production" (Beauregard, 2006, ix). This shift from an industrial based to a corporate based work force accompanied the surge in post-wartime urban jobs and Americans and immigrants alike flocking to city centers. As Schoenauer $(2000,413)$ points out, "populations increased dramatically, not only 
because war industries attracted thousands of workers from rural districts and small towns, but also because thousands of urban immigrants from war-ravaged countries flocked to American cities" and the flux in population, with consumer needs in tow, levied shortages and provided continual economic development. With more people living in urban areas than any other moment in American history, urban housing options were ill-equipped to handle such a stark increase.

Figure 2:

Better Homes \& Gardens Magazine Cover - March 1947 depicting the initial onset of postwar suburbia and the often agrarian based, country-side retreat imagery used in its infancy.
Begotten from this shift in labor and economic workforce would come a paradigm shift in an American lifestyle. Young couples flocked to the urban periphery, searching for a home environment and a place to build a family. But these young families relished for more than just the modest urban apartment. Dreams of house planning and owning a piece of the

American homestead were becoming increasingly accessible as low home mortgages became readily available and developers began designing "small homes" that catered to this demographic. Moreover, government subsidies, loans and policies "aided this exodus, but what began as a trickle soon turned into a flood" (Schoenauer 2000, 413). It was with the start of suburbia that Americans "rejected[ed] the old-world culture associated with European cities, [and] forged a unique identity out of the suburbs [and] the consumption that made suburban life both desirable and possible" (Beauregard, $2006, x)$. This historical combination of young families, existing economic prosperity, and their young potential for income improvement, fostered the environment to which the suburban lifestyle would not only boom, but continuously thrive. 
The Housing Act of 1949 declared the American housing projection to be "the realization as soon as feasible of the goal of a decent home and suitable living environment for every American family" (quoted in: Wright 1981, 246). While an exceptional handful of suburban neighborhoods tackled the housing shortage using mass production methods in planned communities (i.e. Levittown), "most suburbs grew by accretion" and were far different from the suburbia to which we are accustomed to today (Schoenauer 2000, 415). In fact, Only 1.5 million mass-produced units were "added to the country's housing stock in the two years after the war ended, during which time more than 1.4 million new families had been formed annually" (Wright $1981,246)$. During the late 40's and 50's, suburbia was in its infancy, and most "suburbanites fully accepted the trade off of urban amenities for a new but rustic lifestyle close to nature, which frequently meant an absence of sidewalks, street lighting, municipal sewage systems, water lines" and even as far forward as the 50 's and 60's, it was not uncommon to find suburban neighborhoods with "septic tanks and individual water wells" (416). However, what the suburbs were able to provide, was abundant availability for sprawl, good education and the perception of security.

One of the other major changes to happen to suburbia in the post war era was a change in the variety of home styles found in a single neighborhood. In the 1920's, "developers or subdividers purchased large areas of undeveloped land...platted future lots, installed streets and sewers and then usually sold all or most of the land to small builders, who took a few blocks, or to individual clients, hired their own builder or architects" (Wright 1981, 248). After the Second World War, government financing 
programs changed the way suburbia was built and developed. It now became much more profitable for the land developer to also parlay into home production, a shift that often resulted in 300 or 400 identical tract housing.

However, mass production housing, while often a visual nominal of this era, was not the only type of housing created. Often featured in national publications such as " 5 Star Homes" in Better Homes and Gardens Magazine, many architects and designers provided variety and innovative qualities that reflected new and popular trending styles. This solution was highly sought after and praised by house makers and architectural critics alike, which praised the use of design professionals as the savior to drab mass building productions. For example, architects such as Joseph Eichler and Frank Lloyd Write created beautifully modern homes that were produced using flat roofs, asymmetrical exterior facades and large open plans. While these modern designs proved to be popular, the down side was that the FHA evaluators for government loans did not always see them as a "sound investment" doubting that they would be nothing more than a flash-in-the-pan fad (Wright 1981, 251). Therefore, housing styles such as the "Colonia Revival, Cape Cod, Tudor, Spanish, or a safe contemporary look like the ranch house" reigned supreme and were featured in neighborhoods across the United States (251).

One of the key features of these homes, regardless of style, was a preference for efficiency. While small houses do not seem as synonymous with the suburbia of today, small homes with compact square-footage, efficient interior spaces, and "livable and easy to keep clean", as the ad to which this essay begins suggests, were desirable 
attributes. Due to the large number of new families, American's wanted affordable housing that made moving out of the urban centers possible, not necessarily expansive size. The American dream was simply about owning a home with a yard and room for family in a stable environment to create the "dream life".

Much as the housing shortage set off a boom in the construction and planning industries, as did it inspire hundreds of magazine articles and advertising ventures bent on capitalizing on the services and needs of new or soon-to-be homeowners. Magazines such as Better Homes and Gardens, Life, Parent's Magazine and House Beautiful are only just the beginning to the mass influence the housing boom had on advertising. Their feature articles on housing trends and innovative interiors held an air of technology while pleasing traditional American values and family structure. However, the advertisements sold more than just a product, they sold a lifestyle.

\section{Advertising A Dream}

The American Dream is an ideal that was highly sought after in the post war era. The Saturday Evening Post reported in 1945, just before the conclusion of the war: "that only 14 percent of the population it had polled were willing to live in an apartment or a 'used house'"' (as quoted in Wright 1981, 253). Subsequently, magazines and marketing advertisements were geared towards capitalizing on the surge of new construction and new homebuyers. Paint, Furnishings, lawn care, home loans, life insurance, HVAC systems, garage doors and even washing machines used print advertising that drew upon imagery of the new American suburbia, family values and an emerging young 
Figure 3:

Hotpoint Electric Water

Heater Advertisement in the October 1948 edition

of Better Homes and

Gardens Magazine,

displaying heavily

symbolic images to

influence the booming

new house buying

market.
American dream. As seen on the left, this advertisement from Better Homes and Gardens, dated October 1948, features the image of an infant and promises "safety and dependability" at a "matchless economy" for the presumable young buyer.

However, images of the nuclear family and the beginning baby boom

were not only subject to advertising prospecting. American men were often portrayed as the altruistic family man and suit-and-tie-dawning breadwinner in advertising endeavors. After the war, the advertising depiction of women seemingly shifted as well. While war-time efforts stressed the importance of "women in the work force" in imagery such as Rosie the Riveter, the post war women, on the other hand, were often depicted assuming the role of household affairs and child rearing. Ideals and Symbolism stressed that the American Dream was one of family and at its core was a home that was achievable to foster the future.

While traditional gender roles often reigned supreme in print advertising, men and women were often encouraged to work together to create their dream. Looking at house plans and discerning between needs and wants was a common theme before the end of the war, as advertisers and publishers capitalized over the anticipation for the housing boom to come. After the war, their focus shifted to implementation of housing practices, as images of family and how to live the American dream took over headlines and inspired articles and advertisements. When designing her dream home, the postwar housewife, "like her 'handyman' husband, she took part in the do-it-yourself fad of painting furniture and laying brightly patterned linoleum floors" (Wright 1981, 254). 
Women were encouraged to create a home environment that was stimulating to their husbands, but also conducive to raising a family.

The United States began seeing an increase in national pride and a distinguishable American identity that predicated upon wealth, job availability, unbridled possibility and family security. Much like the images of suburbia conjure up our own meanings and identifiers with its modern evolution, suburbia of the 1940's and 50 's had its share of propaganda and advertisement. Images of family, stability, and prosperity were widely circulated through print format. Images of home, family and the American dream were common themes in magazines such as Better Homes and Gardens Magazine and Ladies Home Journal. Sending women around the country images of what an "American" home should look like, how an American housewife should keep her home, and showcasing fashions in both interior design and architecture was just some of the topics they would cover. In many ways, the print magazine was the hand-guide to American housing, or rather, a hand-guide to a suggested housing standard. This form of material and consumerist culture, led many Americans to believe that their home needed to be a reflection of an ideal, rather than self. What the masses began to judge homes by was not a community or locally created standard, but rather one of mass-produced idealism. 


\section{Dreamy Expectations \& the Reality of the Architect}

"The problem of architecture," he says, "is the elimination of the human element from the consideration of form... I do not think it is possible for domestic architecture to be beautiful, but I am doing my best."

- Character Otto Sllenus, Rise and Fall (1928) by Evelyn Waugh

In the search for understanding the role the suburban house played as a piece of material culture, one often asks who is to be credited for their designs. Who, if any specific person or persons, is to be recognized for creating the styles to which we reflect upon as "iconic" for this peacetime era?

The architect as a noble or fashionable profession has been widely documented in fictional characters and roles in a variety of media before, during, and after this era in Fountainhead (1949) and The Decline and Fall (1928) by Evelyn Waugh. Wouldn't it be safe to assume that the role of the architect had a profound influence on this indelible era?

On one hand, the answer is "yes".... Well, sort of. Homes featured in Better Homes \& Gardens, House Beautiful, and other magazines alike, included monthly spotlights on home designs that gave specific credit to the architect

Figure 4:

Article in the February 1946 edition of House Beautiful, Mr. and Mrs. Samuel Homsey are profiled as a husband and wife architecture group in order to "introduce you to the people who influence your life" (pg.96) responsible. Moreover, the role of the architect was often highlighted and

specific men (or in one case, a husband and wife duo as seen in Figure 4)

were glamorized with full-page spread and a romanticizing review in

Better Homes \& Gardens. The architect was celebrated at times, and was

often looked at as the savior of the post-war housing shortage. However, there existed a struggle of sorts underneath the glossy magazine pages. 
For many architects, there occurred a kind of contradictory paradox when it came to compromising the needs and desires of their clients. At the time of the postwar housing boom, excitement over the opportunities that theses houses provided was heightening. As discussed previously, machinery and manufacturing that had previously been cut due to wartime efforts were shifting back towards domestic production; and the possibilities over the growing economy were tempting. This new technology was poised to provide "the latest in building technology... paired with the needs of a modern family" (Clark 1986, 200). As architects dreamed that "'if one were to take the best planning ideas, the best structural schemes, and the best equipment that have gone into the best modern houses, and combine them appropriately in a single house, the result would look like something out of the day after tomorrow'" (as quoted in: Clark 1986, 201). "Tomorrow's House", as it was termed by Architectural Forum, was invigorating, exciting, and was seen as the "integrated, highly individual expression of how a twentieth-century family lives" (as quoted in: Clark 1986, 201). However, the bridge between this technology driven aura and the private realm was not always an easy one to traverse.

In an attempt to understand the exact desires of the burgeoning homeowner, many magazines turned to the social science surveys of public opinion $(1986,201)$. In magazines such as Better Homes \& Gardens, Good Housekeeping, Ladies Home Journal and the like, "between 1936 and 1950, more than forty-one surveys were conducted" such as "Walter Adams for Better Homes and Gardens in 1946, based on a questionnaire answered by 11,428 families" $(1986,201)$. The findings of such survey were quite telling 
of the dichotomy of needs and desires of the homeowners, and additionally, the often muddied waters that the architect had to traverse between their clientele's requests and their own expertise. The study found the "typical American" who had consulted with an architect, builder or developer was looking for new construction in the suburban countryside, rather than preexisting or historic home in the urban center, and their preferences on style were polarizing. While on one hand they were attracted to the tremendously popular "Cape Cod", they also wanted space and favored the "low, rambling style called the Ranch House" $(1986,201)$. Most of those surveyed wanted a basement rather than a second story, a "multipurpose" room but a separate formal living area, open space but with cozy textures, an eat-in kitchen for lunch and breakfast, but a separate dining area for dinner.... and hoping to build for under $\$ 5,000$ (Clark, 1986, 201-2). In short, the young "typical" American homebuyer wanted a lot on a small budget. Traversing the homeowner's wants and their needs posed a challenge to architects who also wanted to express their own style.

In response to Walter Adams' survey, architects noted that homebuyers would ultimately have to compromise, but in fact, the architects themselves struggled with the same issues. While some architects liked basements, others did not, some saw the combination of the living-dining-kitchen open plans as atrocious, while others found it the "wave of the future" (Clark, 1986, 203). Trying to figure out how to compromise function and style without compromising budget was the ultimate design challenge for the middle class. However, the battle between design and affordable execution was only the beginning of the architects' problems with post war housing. 
While many home magazines and architectural journals attempted to accentuate the role of the architect and a scientific approach to understanding the needs of the American homebuyer, the reality was that the professional architect was losing the battle in the suburban home front during this period. Commercial homebuilders and developers were beginning to take a bigger piece of the pie, and handy-man husbands were being encouraged to go out and build on their own. Moreover, escalating prices in materials and construction made consulting an architect a strain on the family budget when "affordability above all" was the primary goal. As architect Frederick Gutheim openly distressed: "even a 12 percent fee on an expensive $\$ 15,000$ house would not cover the office costs of lengthy consultations with a client, let alone the expenses of drawing up the plans and checking on construction" (as quoted in: Clark 1981, 204). To combat this decline, as well as influence home design at a national scale, Magazines such as Better Homes \& Gardens printed a national publication featuring architect designed homes in order to make plans more affordable and available to the cash strapped consumer. While these pamphlets made better design more available, the role of the architect was secondary or tertiary to the design process and often blind to any regional or climate factors which would influence the design or construction. Home design based magazines and construction documents companies would hire architects to design their base plans and then sell them to the public in a set. For example, when examining Better Homes and Gardens Magazine, featured home plans would declare the name of a prominent architect responsible for the design. 
However, the detached communication lines between the architect and the homeowner was not the only factor that would lead to a national building aesthetic. Mass production in the manufacturing industry and in home construction (i.e. Levittown, Sears Catalogue Homes) had an increasing hold on the housing market, and subsequently influenced expectations on home design. Design magazines, advertisements, newspapers and architectural journals were all documenting the rise of the mechanization of the home, whether it is in its production or in the various systems and furnishings that would go into its interior. Homeowners now had an ever-increasing medium via media to explore, be influenced by, and replicate styles and building trends from across the nation. And as information and media circulation continued its increase and as the production of the home becomes increasingly industrialized during the same period, the same home became easily repeatable nearly anywhere in the nation.

Ultimately, the American Dream was one of homogenization and reaching the bar of success set by your peers; keeping up with the Joneses is a prime example of this phenomena. A national building aesthetic only further popularized and perhaps glamorized the idea of living in a suburban neighborhood. And while there are numerous reasons for the suburban success, the unfortunate byproduct was the further segregation of the architect and influence over the "ordinary" home. 


\section{Self and Suburbia: American Dream via Dream House?}

ure 5:

Ivertisement for The Itual Life Insurance Group turing a Cape Cod Style me and the caption "Our eam House came closer lay" showing both post $r$ housing and the nection with dream-like meownership goals. tter Homes and Gardens gazine, November 1948, 177.

In many ways, the "American Dream" slowly morphed from an intangible metaphor for prosperity to a palpable item for consumption: the single family home. With row after row of builder-grade homescapes, desirable American housing became definable in terms of which neighborhood to which you resided more so than any district, block or borough. Homes were

becoming mass-manufactured; and while Sears Catalogue homes had been available previously, after the war, the trend exploded. Home plans were available in nationally published pamphlets, Better Homes \& Gardens Magazine began showcasing homes (with plans to order) each month, and Levitt \& Co. began building their tract homes at un-seen rates, just to name a few. The American house was becoming a commodity; and the American Dream could be purchased in the glossy pages.

However, the American Dream was much more than just a house built of wood and plaster, it was, in many ways, the physical manifestation of culturally significant symbols and values. Suburbia thrived under the sheath of security and family morals. In "suburbia" one could afford a home as a young family with room for a private yard and a personal garage; while the urban streets offered close or even shared living quarters seeded with crime. Moreover, the banality of the suburban-scape offered up clues to the similarity in demographic of its residents. While anonymity can seem negative on the surface, there is a certain security in the notion of surrounding yourself with people who look, think, dress, and ultimately live, like you do. In the post-war suburban house 
there existed a conflicting standard of living. Much like the perfectly analogous detached houses lined the streets of suburbia, there was a certain amount of independence in the single-family home, yet still existed the appearance of conforming to a uniform American Dream.

While safety and security were tantamount with the selling of suburbia, the idea of owning a home was an idea that fueled the urban exodus. The "American Dream" and "affording a home" are, for many, synonymous: "no American Dream has broader appeal, and no American Dream has been quite so widely realized....and if, like other American Dreams, this one is imperfect, even fatally flawed, it is also extraordinarily resilient and versatile" (Cullen 2003, 136). The American Dream was about living the dream life, raising the dream family, and occupying the dream house, regardless of income.

However, the creation of the American Dream comes from the strong sociocultural connections we construct between house and home; and this connection was paramount to the success of suburbia. The "house" is a structurally independent space that is examined for its composition of interior spaces, exterior decoration and geometry, and materials. On the other hand, "home" is a socio-cultural construct as an independent place that holds specific meaning, memory, and tradition in a subjective sense. However, it is also important to understand that the use of these two terms interchangeable also have ramifications outside of the realm of architectural inquiry.

Suburban developers and media propaganda are in the business of selling "houses" under the veil of selling "homes", both today and in the post-war era. As 
Rapoport $(1995,2005)$ describes, equating house with home simply reinforces continuing ambiguity in understanding the manner in which individuals identify with their place of residence. In essence, the idea of a home is emotionally loaded and suggestive. It holds strong cultural and social ties to the imagery of family, and in this case, the American dream. Understanding the consequences of these two terms, and perhaps their interchangeable use is vital. Moreover, the use of architectural design features as an indicator for family values or of social successes was a predominate theme in post-war housing.

Using the terms "house" and "home" synonymously was a marketing ploy that also translated into the personification of inanimate home features as well. The ability to turn space into place was paramount in the success of suburbia. "Small spaces" were merely a way of spending quality time with your close ones, rather than a compromise. New rooms within a home were advertised to perspective buyers as having real, tangible, evidence of improving family life and interpersonal relationships. Items such as the "kitchenette", evoking archaic farmhouse kitchens of utility, and the "activity area" were new additions to the domestic vocabulary, as their inclusion in home designs were predicated under the ideas of "togetherness". In many regards, features of home designs were supported by their "ability" to facilitate family, promote personal gains, and provide an aspirational lifestyle.

Ultimately, the success of suburbia was not in its affordable nature, nor in its vogue-esque advertising of styles, colors and trendy features, but rather that symbolism of purchasing a home fulfilled socio-cultural norms of self and success. Moreover, it is 
understood that "more often than non there is no specific definition behind these terms, dream house or American dream, but rather a general understanding that there are opportunities to be realized or goals to be fulfilled" (Archer, 2005, xv). The American Dream was a truly a continual creation of house, home and self.

\section{Interpreting Form, Function and Style}

Figure 6: Better Homes \& Gardens Magazine: December 1948, seen on pgs. 5455 \& cover photograph.

Title: "A Ranch House from $a$ Ranch Country".
As an object of material culture, the suburban home has within its walls an element of history, tradition and memory of both the family to which it shelters and the culture to which it resides within. Our homes are our modern day artifacts as a representation of our desires, our behaviors, our gender and societal roles, our values and ultimately, our way of life. While it is important to understand the defining elements that demarcate one housing style from the other, it is also inherently important to understand the socio-cultural factors that shape form and function as well. The following sections detail a select group of homes that are indicative of the postwar era.

\section{The Suburban Ranch}

"Ranch houses are not just a matter of picturesque exteriors with wagon-wheel and heigh-ho silver décor. What they can offer is a better way of living - not just a fancier façade."

Will Mehlhorn, "Ranch Houes Suit Any Climate"

(As quoted in: Clark, The American Family Home, 1800-1960, 1986, pg. 193)

While many housing styles go in and out of "vogue", the American ranch, with its low lying roof forms, linear geometry, and archetypal symbolism of shelter, is a style that still appears in new construction today, and the discernable beginning to a comprehensive analysis. Its prevalence throughout suburbia is telling of its popularity, 
Figure 7:

Floor plan accompanying home design at top of page. Floorplan shows the rambling nature of the ranch style house and the organization of interior space.

Better Homes \& Gardens, December 1948.

but the ranch house as a style had a lot variation in terms of its

flexibility. But this style of housing, while young in comparison to the

Victorian or the cottage, is not necessarily new or ground breaking. In all actuality, the ranch was a style that drew upon the bits and pieces of others. Strikingly similar to the bungalow, the ranch takes on a kind of low-lying, rambling type of organization that gave the appearance of space, minus the front porch. In fact, the suburban ranch what one might term, a sort of compromise, a middle ground of style, as you will. The ranch allowed for a wide range of stylistic influences, from "stark and modern to vaguely Spanish or colonial" (Hunter, 1999, 166). It is spatially open and modern enough to grab the interests of some, while drawing upon symbolism of the American countryside and traditionalism of the preferences of others. In fact, "Sunset magazine went even further to suggest that the ranch house was not so much a style as an 'approach to living'" (as quoted in: Clark 1986, 211).

As Americans were moving out to the urban periphery, building suburbia on the countryside, and the imagery of the ranch on the frontier, was paramount. Various media publications began building the imagery of suburbia as a place of wide open space and peaceful living; and the design of ranch fit perfectly into this picture with descriptive vocabulary such as rambling, sprawling, big and breezy. The editors of House and Garden magazine "praised the low profile of one Oregon ranch house for the way in which it blended into the natural landscape" stating specifically that the house was both very "'personal and yet a thoroughly adaptable background for good living'"(Clark, 1986, 
211). The ranch was modeled to the average American new homebuilder as the option for bringing the sprawling space of the open wild in the often small and tight lot spaces allocated in the consistent suburban landscape.

Again, the ranch home was often marketed to the American homebuilder and buyer as an option to bring big country living to the budget conscious and space strapped client. Creating the conceptual image of an agrarian American lifestyle, advertisers played heavily upon the socio-cultural symbolism of a simple, wholesome, clean and airy kind of existence that only the country could afford. The ranch's popularity was predicated upon "a new ease of living, climbing stairs was an unnecessary and outdated form of work" with an orientation opening toward the backyard. (Hunter 1999, 166). Since many of the new, young homeowners were moving out of their cramped urban apartments seeking suburban solace, the ranch provided a literal interpretation of the semi-urban countryside.

Additionally, many home magazines implore that the "universal appeal of the ranch house was its simple efficient look" and is often pictured in a serene country landscape (Clark 1986, 211). As the description depicts in the Better Homes \& Gardens Magazine December 1948 issue:

"Authentic, tho, is this small ranch house... low, rambling, and thing thru the middle, it stands on the rolling acres of the B.E. Tade fruit ranch near Phoenix.... But this ranch house is one that doesn't require an acreage for proper setting. It's 58 feet wide. But only 48 feet from the front of the garage to the back of the bedroom wing. These unusual measurements make it ideal for a city lot that is 
wide and shallow. It's perfect, too, for a corner lot where it is desirable to have the house face the lighter traffic of the side street." (Pg. 55)

The strategy behind using actual ranch homes to promote suburban prototypes turned out to be a marketing ploy that was utterly successful. Drawing upon imagery and cultural symbolism for a piece of their "home on the range" helped to catapult the home style to the number two spot on units sold and constructed during the post war era.

But what was it exactly about this home style that made it so utterly irresistible for the burgeoning homeowner? The low, linear nature of the exterior draws the eye across the lot, and creates the illusion of expansive square footage within the interior. A defining feature that distinguishes the ranch is also the orientation of the roof slope and gable style. In the "typical" ranch home, the main pitch of the roof often slopes front to back, with an open gable on the sides, allowing for the broadest side of the home to face the street. While the previously popular bungalow roof has an open gable facing the front and accentuated eave brackets, and dormers, in a ranch, the roof line was very simplistic, often uninterrupted except for the chimney, and had wide overhanging eaves without brackets or ornamentation. As one historian notes, a common advertising ploy of the ranch was to portray "the long, low silhouette with a gently sloping and overhanging roof sheltering the house against sun and rain" (Clark, 1986, 211). Moreover, the notion of space and airy indoor/outdoor living was a design feature that was of foremost importance in the success of this design. Most ranch homes featured "picture windows or sliding glass doors between the family living 
spaces" that allowed the user to enjoy the outdoors for recreation or to have a second eating area when the weather permitted (Hunter 1999, 166). Such a porch was different from the cottage or bungalow styles in that it was level with the foundation slab, much like a patio, and was not been adorned with heavy columns. A large picture window placed in the living room, a trait that was common in many home styles of the era, also helped to bring light into the low lying, den like interior. The ranch style was all about enjoying the sprawling nature that the countryside and urban periphery had to offer.

Ultimately the ranch house cemented its place among the most popular suburban homes because of its design foundation on utility and cost savings. While the low lying nature of its design helped to create the illusion of large interior square footage, it also allowed for building costs to be considerable lower than other suburban housing styles. The low interior walls and low-pitched roof cut down costs on raw materials, which subsequently kept heating and cooling costs low. Moreover such ranch homes were predicated upon the idea of open and airy, "cross ventilation is an inherent property of detached homes and so is the open-ended possibility of favorable orientation" and in the case of the ranch, "low-profile dwelling prototype, the single family detached house is easily integrated into a natural setting and enjoys a privileged status in municipal zoning considerations" (Schoenauer 2000, 420).

Moreover, the materials often used to build the ranch home focused on the marriage between form and function. In such case as the home design from Better Homes \& Gardens Magazine from December 1948, as seen in the heading of this section, featured "wide boards with joints covered by battens, one of the least costly 
methods of construction known" (55). Moreover, small bedroom windows and a typical centrally located hearth, allowed for low construction costs and energy savings once the home was occupied. On the interior, similar design features predicated on utility and cost savings continued. Materials often featured in these homes included "plank walls and ceilings" and kept "plastering to a minimum" in order to build these homes in a speedy manner on the contactor side, and reduce maintenance for the homeowner (Better Homes \& Gardens, December 1948, 54). Whether built in a pre-fabricated fashion or independently by a home-builder, the ranch home with its wood construction and low-lying interior were inherently cost-conscious.

\section{Quad-section of the Ranch}

Utility and efficiency were of upmost importance when designing the ranch. Looking at how the interior and exterior relate to one another, it becomes apparent that there is a kind of compartmentalization of utility, public, and private spaces occur when organizing the interior. Such sections in the ranch design have ramifications on both the geometry of spaces on the interior and locations of defining stylistic features on the exterior, both of which will be detailed subsequently.

Figure 8:

Floorplan of a FHA approved ranch home showing the allocation of interior spaces and significant architectural features. Note the orientation of bedrooms, centrally located entertaining space and kitchen/utility area near the garage. Direction of sightlines are towards the back of the home with a screened porch rather than a front porch for added privacy.

"Your Postwar Home and Building Guide" (1945),

National Homes Inc... St
The utilitarian aspect of the quad-section in a ranch is used in two pieces of the home through the garage/carport and the laundry and kitchen spaces. Whether the ranch home features a garage or carport, the shared utility entrance into the home connects to either a mudroom/laundry space or into the kitchen. Both of these spaces are regarded for their service qualities and typically flank the home 
interior on one end or the other, directly adjacent to the living and dining spaces. By placing these areas together, it allows the homeowner to directly unload groceries and goods from their car, while also providing direct access to the side or backyard.

Moreover, by placing the utility portions of the home in the same section, efficiency and space savings are maximized.

The next portion of the quad section is the public spaces of the home: the living and dining room. In the typical ranch home, these spaces are often placed in the center of the interior layout, which provides the ranch with its specific, style defining traits. On

Figure 9:

Accompanying exterior rendering of ranch home. Showing horizontal roofline and centrally located front door.

"Your Postwar Home and Building Guide" (1945), National Homes Inc., St. Petersburg, FL, 28-29. the exterior, the placement of the centrally located public spaces allows for the front door to be placed almost directly in the center of the front façade. This specific location allows for a visual break from the long, linear lines of the ranch and provides a clear directional cue for a formal entrance.

Also, breaking up the exterior visual lines is the central location of the hearth along the roofline in the quad-section of the ranch.

Breaking up the typically long, low central pitch of the roof, the location of the hearth also leads to interior benefits of providing heat to the central core of the home in an efficient manner, while also giving the interior cues towards organization of space. In the ranch style, the hearth and chimney is typically a celebrated design feature, often mimicking the boxy, stone cladded, foundation features on the exterior. Organization of the interior also seems to focus around the hearth as a place for gathering. Dining 
rooms and living spaces seem to flow together as a kind of practical, yet family oriented, organic interior configuration.

Finally, the fourth section of the ranch is the private bedrooms. Often sectioned off separately by a hallway, the sleeping areas are typically located on the opposite side of the interior from the utility sector of the home, as one of the flanks to the living rooms. In the immediate post-war era, restrictions on size and building funds often translated into a single shared bathroom and equally proportionate sized bedrooms. While this could be attributed to design holdovers from a historic sensibility of design

Figure 10:

Better Homes and Gardens Rambling Ranch, by John Normile A.I.A featured in the June 1947 Issue, showcasing the flexibility and rambling nature of the ranch style suburban home., architectural form and design features.

Figure 11:

Accompanying plan showcasing orientation of interior space, quad section layout and location of significant architectural elements. and previous urban building styles, the inclination towards small, proportionate bedrooms would have also allowed for fund allocation towards communal spaces. Moreover, the location of these bedrooms is indicative of the same inclination towards privacy as many traditional two-story farm homes, with the bedrooms being in a separate sector for sound, and traffic control. The sleeping sector of the home allows for increased privacy and efficient sound control throughout the space.

The quad-section of the ranch ultimately allows for increased efficiency and practicality when planning out the home for personal preference and site-specific factors such as terrain and slope. The sectioning off of the interior space also gives the ranch its distinctive long, low and rambling style. In fact, in an article titled "It Rambles Where You Want It" in June 1947 of Better Homes and Gardens Magazines, the ranch is celebrated for these exact qualities: 
"The same freedom of design that left the huge, old trees untouched gives you a chance to shift living areas around to fit your site. It's like playing with blocks.

There are four basic areas, all at ground level - garage, dining room and kitchen, living room, and bedroom wing. Your might want to shift the bedrooms back to avoid street noises; your architect can easily make the change. Or you might decide to move the garage around to make it accessible from a side street. You might even reverse the dining room and the kitchen to take advantage of sunlight or a view. That's the beauty of this plan. The house rambles - but it can be made to ramble exactly where you want it."

- "It Rambles Where You Want it", Better Homes and Gardens (1947, 38-39)

Figure 12:

Modernist Ranch Style Home. Better Homes \& Gardens Magazine. July 1947, pg. 42.
What made the ranch so popular was perhaps the use-ability it offered to its residents and the ability for the home to be modified to fit the unique requirements of each build. While the organization of spaces via utility, public and private remain the same regardless of

home orientation, the ranch home undoubtedly allows for flexibility when it comes to the various factors that influence suburban design and homeowner preference. Modernist Influences on the Ranch

While truly modern homes deserve respect and research as a style all of their own (a style which will in fact be detailed in a subsequent section), it is important to note that there have been variations in modernist design influences on the ranch home. What has made the ranch home as a design style visually desirable and stylistically flexible is that the ranch home acts as a kind of middle ground on post-war suburban 
style. While in many cases the ranch draws upon exact imagery of the range and country-esque lifestyle, the low, sprawling design left it impressionable for influence of other design powerhouses. While the ranch home never truly became a modern work of architecture in the pure sense of the term, the ranch design of a home was often used as a base for modern design influences and experimental design.

Figure 13:

Accompanying Floor Plan of Modernist Ranch Style Home illustrating the design placement/orientation.

Better Homes \& Gardens

Magazine. July 1947, Pg. 42.
The Prairie Style, as defined and designed by American

architect Frank Lloyd Wright, had been around for decades by the time the post-war suburban boom began. And much like the ranch, the Prairie Style predicated its design influences off of the rambling country landscape and long linear lines of space. By the time the ranch was gaining in popularity as a staple in suburban design, variations to the ranch style began to lean towards a mixture of modernist design and Prairie Style principle foundations as a way to make the ranch

seem fresh and new, yet grounded and focused on family togetherness. Truly modern and Prairie Style home designs are predicated upon clean lines, a honest and often times raw expression of materials and finishes, and an emphasis on openings and geometric forms. In the case of the ranch, linear foundation walls, large over-hanging eaves, and low pitched roof forms were already a design principle, but with the introduction of the modernist influences, these traits became exaggerated to form a kind of hybrid.

On the exterior, the front façade kept the air of privacy with a heavy, low lying eaves and a centrally located front door. However, material changes on the exterior and 
the exaggeration of openings and lines seem to be the defining characters on the outside. In an effort to mimic the natural or "organic" design of the Prairie Style, horizontal shelf walls became bold, reaching up onto the façade as a kind of large foundation, and are cladded in stone. The front door becomes recessed to both call attention to the opening and to shelter the guests from the elements. The front windows, often small and square on the traditional ranch home, are now larger, rectangular and celebrate the connection with the outdoors. While the exterior geometry is very linear and low-lying with all ranch homes, there is a further exaggeration of the horizontal elements in its modernist expression.

Figure 14:

Photograph and

Rendering of residential options for indoor/outdoor blended landscaping and planter options found in modern ranch style homes.

"Indoors and Outdoors are Planned as One", House Beautiful, May 1946, Page 89
On the interior, the connection between the interior and exterior was enhanced through materials choices. As seen in the floorplan from Better Homes \& Gardens July 1947, stone flooring from the exterior pathway and porch are carried into the entrance and public spaces of the interior of the home. Moreover, interior features also began to mimic the cladding of the exterior. Full stone fireplaces often mimic the geometric, horizontal nature of the foundation walls. Other features often included

the use of interior planters as room divers, bringing into more stone and natural plants to the interior, and full length doors and windows that open up to the backyard or garden.

Inherently, the main differences between the modern take on the ranch and its traditional counterpart was the expression of the openings and materiality between the two styles. Organization of space, clean lines, low-lying and balanced geometry was a 
signifier regardless of taste. However, what is also important to note is that the modern interpretation of the ranch was undoubtedly a signifier of a higher budget. Larger windows, stone cladding and the like would have come at a higher cost and would have been implemented by more established post-war homeowners.

Why the Ranch?

The organization of the ranch interior, with sectors based upon usage and privacy type, allows for a very efficient model of building, movement, energy and resource usage, and sound control. What makes this style of residential abode so able to transcend decades of stylistic preferences, family sizes, modifications of gender roles, demographic of users, and varying environmental location is that the ranch home, in its very essence, is ultimately its efficiency.

What allows the ranch to continue to be a part of our modern residential landscape is that it is both efficient to build and efficient to live in. While two story structures are efficient in land-use, per se, they tend to be difficult when it comes to accessibility. Whether it be a new family or an elderly couple, the ranch style of home is applicable to nearly all stages of life. While differing types of the ranch in terms of stylistic preferences have popped up over time, the ranch has undoubtedly made its mark on the American residential landscape due to its foundation in usability and flexibility. 


\section{The Cape Cod}

Figure 15:

Oxydol promotional

sweepstakes with the prize of a

Post-war Cape Cod home, showcasing the popularity and desire of this home plan and style. Better Homes and Gardens Magazine, October 1947, Pg. 196
While the Ranch House was one of the most popular and enduring home styles to emerge out of the post-war suburban era, during this iconic period of home building, no other housing style reigned supreme over the Cape Cod. With its small foot-print, compact interior, clean lines, steep pitched roof, and even geometry, the name

"Cape Cod" was an indicator of its origin, but not its sole locale of construction. In fact, the Cape-Cod, would be one of the most prevalent go-to choices for early suburban housing developments across the nation. Whether it be in noted in sheer amount of homes or its prevalence in ads and marketing schemes, the Cape Cod was everywhere.

Perhaps one of the most notable variants of the cape cod that is shared by many Americans when prompted to think of the post-WW2 housing is the Levitt town home. It should be stressed that Levittown is an "exception" and not the rule, as the majority of suburban homes during the post-war era were not found in Levittown or in one of its twin-like neighborhoods built by separate developers. However, it would be almost impossible to not discuss this era of residential history without bringing this subject to light. Levittown undoubtedly aided in the symbolism associated with the Cape Cod and postwar suburbia as a whole.

Featured in countless accounts of suburbanization, segregation, hominization, middle-class mobility, and suburban planning, Levittown is often used as the shining example of housing success, or the scape-goat for socio-cultural private-sector problems. In many ways, Levitt \& Sons may be perceived as villains of housing, inciting 
the demise of meaningful architecture. Cranking out cheaply made homes in a "quantity over quality" kind of mentality, the cracker-jack communities that his company created were also fiercely segregated in the name of consumerism. In an infamous 1954 interview with the Saturday Evening Post, Levitt commented that his company could either solve a housing issue or a racial issue, but they would not be in the business of tackling both simultaneously. His choice to serve the former, speaks not only to his own personal stance on the subject, but perhaps the unfortunate legal and social injustice of a nation. Because of these factors, a dark mark will always remain on the Levittown endeavors. In fact, Levitt's New York Times Obituary famously noted that he was the creator of "the insidious archetype of a dehumanizing world of uniformity" (Quoted in Pompilio, 2014). Such attacks on Levittown and the developer himself, forced Levitt to go on the defensive, using popular magazines and media to fire back at his critics in a very public manner. Writing in Good Housekeeping, Levitt asserted that his houses were not dull nor conformist, regardless of their seemingly conformist tendencies (Clark, 1986, 227).

Figure 16: Advertisement for The Imperial Glass Corporation modeling crystal-ware after the Cape Cod due to its "beauty", "tradition" and "sturdy durability". Featured in Better Homes and Gardens, April 1948, Pg. 192
While architectural critics will fiercely debate on whether to hate the player or the game, what is an unarguable fact is that Levitt \& Sons took a consumer demand and supplied it with a housing style that was undoubtedly popular. The unfaultable star of the suburban landscape, whether it be in a Levittown community or in any other suburban construction endeavor was the Cape-Cod. Drawing upon traditional style with the efficiency of the modern 
industrial era, there are numerous accounts of how the Cape-Cod managed to intertwine utility and stylistic preferences.

But what made Levittown so popular and publicized? How was the Cape Cod instrumental? What about its design made it so successful? For start, perhaps we should look at the man who built Levittown himself, for the answer:

"The veteran needed a roof over his head, instead of giving him just a roof we gave him certain amenities," Levitt explains. "We divided it into sections and we put down schools, swimming pools, and a village green and necessity shopping centers, athletic fields, Little League diamonds. We wanted community living." - William Levitt, as quoted in Esquire, December 1983, "The House that Levitt Built", Ron Rosenbaum (378-391).

Or examine the news publications of the time for the answer and opinions of the era: "The influence of Levitt \& Sons on housing goes much further than the thresholds of its own houses. Its methods of mass production are being copied by many of the merchant builders in the U.S. .... The countless new housing projects made possible by this financial easy street are changing the way of life of millions of U.S. citizens, who are realizing for the first time that the great American dream of owning their own home. NO longer must young married couples plan to start living in an apartment, saving for the distant day when they can buy a house. Not when they can do it more easily than they can buy a \$2000 car on the installment plan.

- "Up From the Potato Fields", Time . July 3, 1950. (53) 
And again:

"As soon as one of the first 1,800 veterans to rent a house in Levittown has been there a year, he is given an option by Levitt to buy the house for \$7, 990; if he does not buy, Levitt will rent for one year more. "I think they'll buy alright," he has said with a pride anyone might reasonably take in watching well--made plans come to fruition. The veterans will be backed by GI loan and will thus require no cash, they will get back a \$100 deposit from Levitt, and the carrying charges on the loan will be less than the rent they are now paying--a combination difficult to resist. . . . The 1947 price on the basic small [Cape Cod] Levitt House was \$7,500."

- "The Six Thousand Houses that Levitt Built", Harper's Bazaar Magazine. (1948, 79-83)

Much like the ranch, utility was important in the construction of the Cape Cod, especially in the case of Levittown. However, the utility in the home was not necessarily for the homeowner. In the case of the Cape Cod, the utility was found for the builders themselves. While pre-fabrication had been a form of construction used in the previous decades (i.e. Sear's catalogue homes), in the 1940's and 50's, the conveyor system of war-time production translated into home building through "large-scale system of streamlined, on site construction" (Hunter, 1999, 160). Rather than producing homes on an "assembly line and moving them to a final location, this system, in effect, created a factory on the site itself... [and] took advantage of the new industrial materials of efficiently" (1999, 161). 
How the Cape Cod, in particular, fit into this mold, was because for a fairly basic fee, the home could be constructed to living standards with only half of the home finished, leaving room for additions or finishing construction at a later date when the family became more established. Moreover, the small footprint (first versions were between $750-800$ square feet) allowed the contractor to keep expenses low, and still provide enough lot space for a car to be parked along side, and the broadest side of the house to face the street for visual appeal (Hunter 1999, 160). Although these homes were sized a lot smaller than the mail order bungalows of the early 1900's, the appeal of these free-standing single-family homes with their affordable price gave them massappeal (160). Their cheap production costs made them affordable to purchase and produce, a duo that would make this home seem ideal.

\section{Cape-Cod Characteristics}

\section{Figure 17:}

Advertisement from

Standard Homes

Company showing the

"ideal home" of a Cape

Cod.

Better Homes and Gardens

Magazine, April 1948, Pg.

237
Much like the ranch, a kind of exterior balance and simplicity in design was commonplace when it came to the design of the Cape-Cod. On the front façade, a centrally located front door would be flanked with small casement windows. Cladded in siding or shingle, the cape-cod featured hardly any ornamental adornment, except for the occasional faux shutters. A small, minimalist entablature or an occasional faux lintel decoration was about the limits of ornamentation on the post-war cape cod, a decision which could tie its roots back to a touch of modernist style or perhaps simple budgeting on needs vs. wants. 
The only brick typically found in the home would have been on the small, narrow chimney. Moreover, unlike the ranch, placement of the chimney held no regulation or standard location. A feature of the home design that was often downplayed and over simplified, the chimney was not considered to be a defining trait in the house's design style, but in this case, the absence of a trait can also be a defining feature.

The narrow chimney would have also been fairly tall to accommodate for the most defining feature of this home design: the roof form. Much like the ranch, the rooflines would slope towards the front street façade and backyard, leaving an open gable at either end. However, the differences begin with the roof form itself. It featured a very steep pitch, which would allow for an un-finished attic space in the basic models, and would include two dormer windows facing towards the front in those who had the means to finish off the space, thus defining its feature as a "one and a half story" home.

Figure 18:

Popular breezeway design options with accompanying description on design and functional abilities of the spaces. While this design feature was often a luxury, their inclusion was often paramount to porches or patios in Cape Cod style homes.

Article is found in the April 1944 edition of Better Homes and Gardens, Pg. 31.
While a carport or garage would have been considered a luxury at the time (often added after the original construction), those who did include them in the design often connected them to the primary residence through the use of breezeways. Breezeways themselves are found in a variety of post-war home types (colonial, dutch colonial, bungalow, to name a few) and were a popular design choice due to their multi-functional properties. Used as a outdoor dining spaces, utility areas, gateways to private outdoor spaces, or a way to frame the

natural landscape, breezeways within the Cape Cod were a way of forging design form 
and function. Moreover, in an April 1944 edition of Better Homes and Gardens

Magazine, there existed a moderate amount of variety in design form and options for a homeowner to include in their house design.

When it came to placement of interior organization, the same characteristics of balance and simplicity held true. With a centrally placed front door, the organization of interior spaces was generally planned in a kind of "four-square" orientation: Living Room, Kitchen, Bedroom, and Bedroom; such design interior reminiscent of more established and antiquated home designs. Squeezed in-between these four rooms would be some sort of small bathroom and a stairway leading up to the un-finished or finished attic space. In the case of those houses that decided to finish the second floor, the option was available to increase living space and move the private bedrooms to the second floor.

\section{Figure 19:}

"The Inwood" variation of the Cape Cod Design approved by FHA standards in 1946. Four square orientation of interior spaces are found on the main level with a "developed attic plan" for the second floor should the homeowner decide to finish at additional cost. Design is typical of base model Cape Cod with add on options to increase space and luxury.

"House of the Month" Book of Small Houses, Harold E. Group, New York, 1946.
The location of plumbing and utilities are placed within the interior in such a manner to conserve space and materials during construction. Whereas in older home styles such as the Victorian or the Craftsman would have placed the bathroom between the two bedrooms, the location of the bathroom would have been placed near the bedrooms but also next to the kitchen (Bacon Hales, "Building Levittown"). Doing so would have allowed for a shared plumbing wall between the kitchen and bathroom, cutting down costs on expensive piping and keeping the installation time (and added expense of services) for plumbers down. 
When funds allowed, a large picture window facing the front façade of the home was an attractive feature. Small windowpanes kept the traditional look of the Cape Cod true, and the added light into the small, low ceiling height interior was a welcomed addition. Whereas the ranch home opened up its interior to a backyard or patio, the Cape Cod opened itself up towards the front yard, framing the picturesque smooth, green lawns and minimalist front landscaping.

Figures 20, 21, 22:

Furniture Article displaying popular products from Macy \& Co. and Tapp Inc. Furniture pieces displace utility, multiple-use, and lightweight pieces for the post-war home. Frances T. Heard, "Postwar furniture will be more useful" for ultimately "better living".

Better Homes \& Gardens Magazine January 1946, Pg. 55.
Interior furnishings of the Cape Cod were also indicative of the same functional, clean, and traditional nature that inspired the exterior features. Simple, light wood furnishings contrasted from the dark, and often times heavy, furnishings of the Craftsman or Victorian style. Clean lines and light on materials, popular furniture of the post-war era were easy to construct and followed a minimalist, yet functional design style that reflected the same building attributes. As seen in the accompanying images, functionality was of the upmost importance with special attention given towards pieces that could perform multiple tasks in various areas of the home. Much like the Cape Cod house design, the furnishings that would have been period and appropriate for the time were marketed for their build-better-not-bigger attitude regarding space savings and functionality. As the article below from Better Homes \& Gardens, January 1946, states, such furniture pieces were "harbingers of better living". 
The same factors that influenced furniture design, also translated into interior finishes and design features in the Cape Cod. Ultimately, final price for the consumer, rising construction costs for the contractor, and high mechanization drove many of design choices. In one such instance, the expression of the hearth on the interior was a feature that was often downplayed and minimalized. While the pre-war Victorian or Craftsman homes had celebrated ornate, and often lavish, hearths and mantle pieces, in the Cape Cod such a feature was expressed in a simple manner. Mantles were created of light-colored wood and would feature clean lines similar to furniture pieces popular during the era. However, still keeping with the traditional styling of the Cape Cod, vague implications of dental, column, or cornice work could be found in more expensive models. Much like the chimney on the exterior, the interior hearth would be minimalist and simple, and feature the only amount of brick located on the home. While these choices would certainly be favored because of their low cost to the consumer and contractor, these features were actually considered very vogue and were celebrated, as seen in the Figures 20, 21, 22.

Much like the space and cost saving measures taken in the construction process of the Cape Cod, so too did furniture and interior fixtures. Whether their inspiration came from the mechanization processes of wartime efforts or from the popularity of other modern architectural styles gaining in popularity, there is no doubt that the style found in the postwar Cape Cod was clean, light, and simple. While its features and fixtures are popular even today, they are nonetheless iconic of a time where utility and function served as design inspiration and purchasing power. 


\section{The Kod-Kitchen-"ette"}

The Cape Cod of years past was stylistically very traditional; however, the PostWar version of the American icon gave birth to a "new-age" design feature all together. Because its objective was predicated upon small square-footage, perhaps the most noticeable new feature of the home interior was the absence of it all together. The lack of a formal dining room was a casualty in the fight against construction costs; and while on face value this would seem as if it would be a scar on the face of an otherwise popular, go-to housing style, the opposite held true. Instead, a new room emerged as the must have of housing design: the kitchenette.

Advertisers and homebuilders began glamorizing the absence of the dining room by selling a new room in the home: the kitchenette. However, selling this new space to the American public took some creative marketing strategies. Using the precedence of

Figure 23:

Banquette seating in a breakfast nook of a post-war kitchen. Seating opens up for added storage and the table expands for additional workspace.

Better Homes and Gardens, "A Double Duty Breakfast Nook", January 1946, Page 108 the American country estate and its utilitarian roots, some advertisers did not use this as a nuance idea at all. Citing the use of the kitchen as a place for communal family living and functional homemaking, the kitchenette was marketed to homeowners as a good use of space, rather than the loss bare square-footage.

Features of the kitchenette included other "ette" furnishings and features. One such piece, the "dinette", a small dining table, was

perfectly functional for a square footage starved interior and offered up stylisitic cues from popular furnishings of the era such as clean lines and lightweight construction. Spawning off of the utilitarian and multi-functional foundation of the post-war era, the 
"banquette" would go on to find future fame as a built-in fixture for years to come. Both options were integrated into the kitchenette as alternatives to save space and materials while functioning as a multi-purpose piece.

The kitchenette provided a compact, yet utility focused, interior space for the new American homeowner. Once again, the fact that this space was small was not necessarily seen as a negative attribute. Advertised to the female audience as a space that was easy to clean and work around was a major selling advantage, a factor that was celebrated throughout the home and especially in the kitchenette.

\section{"Timeless" Dream}

The Cape Cod was wildly successful due to its inherent utilitarian nature, flexibility for future expansion and its perception as a timeless, traditional design style. Evoking design cues from New England, yet constructed around the nation, the Cape Cod was seen as a safe home choice because of its design precedence, unlike other model homes from the era. In a July 1947 article titled "Abracadabra, Shoe Box to Cape Cod" in Better Homes and Gardens Magazine a homeowner is quoted as stating that their design choice of the Cape Cod was based upon its "timeless... early American" nature as "nobody could accuse the Cape Cod as being a 'flash-in-the-pan"'. When building their piece of the American Dream, many homeowners sought the Cape Cod as the traditional American platform to begin.

In fact, the relationship between the Cape Cod and the notion of the American Dream was one that was heavily advertised during the post-war era. In the example to 
fact advertising a free home, but rather 100 dollars a month for life. By showing an image of a Cape Cod with a couple fondly stating "Imaging winning a steady income! We could even buy a home!" shows the implied connection between the Cape Cod and affording the dream life. In many regards, the Cape Cod was the inspiration for an era and a motivation for middle-class mobility. While it was often used as the subject of varied advertisements and publications as the visual symbol of a housing era, what was paramount about its design was that its affordability allowed for a completely new group of Americans to begin to achieve the American Dream.

\section{Prototype Homes:}

\section{"Here's once when the sum of the parts is greater than the whole. For here is a plan whose greatness lies in its details and segments, any of which could be used alone. So study it - not to duplicate it, but to borrow bits and sections - so that your own totally different plan can have greater utility." \\ - House Beautiful, "The First Postwar House”, May 1946, Pg. 87}

Figure 25:

Cover of House Beautiful, May 1946 titled simply: "The First Postwar House" with a color photo of the magazine's choice for the best postwar home design.
With the joy, relief, and pride of winning the Second World War came the promise of power and innovation in the decades to come. The mechanization and industrial manufacturing that had been focused on wartime efforts, was turning back to state-side endeavors serving a consumption-driven population that was on the cusp of an economic and

housing boom. While most of the solutions provided to the American public solved the housing problem with traditional design concepts, there was simultaneously a design movement based upon modern, somewhat futuristic, housing options. Excitement over the endless possibility for postwar housing was at its height, and the design field responded with enthusiasm. 
Although many of these housing types could be considered somewhat of a "flash-in-the-pan" type of phenomena when looking at production numbers or their propensity for subsequent reproduction, when looking at singular pieces of their designs and innovative building technologies we can begin to see how their influence on other housing types was quite profound. Whether these designs were truly conceptual experiments or simply ill-fated housing movements, their role in the post-war housing conversation in nonetheless an important one. The following examination explores some of the niche post-war housing solutions that can be celebrated for the influence of their parts rather than the quantitative success of their whole.

"The First Post-War House"

After the conclusion of the war, many housing and design professionals began anticipating the burgeoning era of peacetime prosperity and held a kind of excitement for the possibility of new and experimental housing options could be available in this

Figure 26:

Photograph of the front of "The First Postwar Home" showing the large overhanging eaves, stone and glass exterior, and the high privacy windows. House Beautiful, May 1946, Pg. 85 new era. In a special edition of House Beautiful nearly a year after the official end of the war, May 1946, "The First Post War House" showcased a house prototype that featured the latest in residential design, building technologies, and domestic products through an "experimental project" in Los Angeles, California. Funded and

promoted by Fritz Burns, one of the biggest United States home-building operators before the war, more than "10,000 man hours of creative dreaming by several scores of experts" combined their expertise to create their vision of the post-war home (House Beautiful, May 1946, 82). 
The intention of the house prototype was somewhat different from home showcases put forth by Levitt \& Sons or other prominent suburban developers during the era. Rather than provide a final base model for prospecting clients to experience and purchase, the home was a sort of sky's-the-limit experiment by architects and design professionals to explore what a home could be and to implement cutting edge design solutions. As the feature article notes, “...it contains some 350 ideas for better living any or all of which future home-owners may incorporate in their plans, or demand if they buy" $(1946,82)$. In essence, the unique house designed for this feature edition, became a custom concept home created in an almost buffet style of pick-and-choose options for residential design and "should be viewed for the meaning of its parts, rather than its whole" (82).

The architectural design of the "First Postwar House" was a unique blend of styles. On one hand, one could see it as a kind of imitation of a Prairie Style Frank Lloyd Wright home with its large overhanging eaves, blending of horizontal stone and redwood panel cladding, and integration of the interior and exterior through materials and glass. On the other hand, its sprawling, meandering style, quad-section of interior rooms and low-lying roof form would lend itself similar to the typical 1940's post-war ranch. However, the un-box line footprint, courtyards and double-U shaped plan was unique and unlike most ordinary homes of the time. Such a design would have provided the homeowner with increased privacy but would have also required a larger lot to create. 
The home was innovative in its understanding of solar orientation and energy saving design solutions. As seen in the floor plan of Figure 27, the south side of the home features a glass curtain-wall to absorb the most sunlight and provide the maximum amount of warmth allowable for such a wall in the winter months. This was made possible in part of "new design techniques and new building products" designed by architects Walter Wurdeman and Welton Becket (House Beautiful, 1946, 84). By implementing "roof overhangs and insulating glass to achieve the sun and temperature control necessary with such [a] large glass area", the design concept is executed in a sophisticated manner. Moreover, the implementation of louvers for shading windows is a forward thinking design solution that was extremely practical.

On the interior, the sectioning off of spaces is similar to the traditional post-war ranch, but with additional luxuries. On the far eastern side of the home the private bedrooms and bathroom are located. By creating a separate wing for these rooms, privacy and sound control were maximized while also allowing for an increased amount of windows on exterior walls. The bedrooms also feature many space saving measures with pocket sliding doors, built-in wardrobes, and a drawing table.

Figure 27:

"The First Postwar House" plan detailing the bedroom wing and open-concept living-dining room area. Also, showcasing the utility sector of the home and the multifunction indoor/outdoor space. House Beautiful, May 1946, Pg. 89
The open-concept living and dining room in the center of the plan employs a very modern take on its décor and fixed features. A wide stone fireplace is reminiscent of Frank Lloyd Wright Prairie Style homes. However, flanking the fireplace are built in spaces for a family radio and television, a very modern convenience for the time. The open concept interior also flows seamlessly into the exterior with the 
use of planting beds, shelves and windows that blur the line between interior and exterior space. The front entrance, which opens up into the living space, is innovative in continuing to blend the indoor/outdoor feel while maintaining privacy. As the detailed article in House Beautiful explains: "front of house faces street so windows are small and high...[the] overhead of roof is tilted up to give windows more light....well-blended materials an flower beds enliven severity of house front.. [and the] wall at left of doorway is of 4' $x$ 8' redwood plywood panels varnished in natural finish" (House Beautiful, 1946, 85).

In the utility portion of the home on the far western side, the stone cladding and clean lines of the carport give a modern take on an often neglected post-war space. A hobby room and storage area is built into the back of this space, enclosed by an overhead door near the backyard for a usable workspace. A service porch, similar to the breezeway found in other post-war homes, connects the carport to a

Figure 29: Rendering of the backyard space detailing the rooflines and the blending of space and materials. House Beautiful, May 1946, Pg. 89 luxurious all-purpose room, which also has access points to the exterior barbecue pit, drying yard, and mechanical spaces. Finally, the kitchen and laundry are combined in a unique and interesting space that is predicated upon a truly utilitarian function. While the orientation of these spaces and the addition of hobby and all-purpose rooms are quitesimply a luxury that not many new homeowners could afford, the inclusion of these spaces in this prototype suggest an interior plan favored on communal living and play space more commonly seen in more current home designs. 
Special technologies and built-in features employed in this home were also very forward thinking for its time. Sunken garbage cans and package doors and trays eliminated unsightly clutter on the exterior. A "front door communicating phone" is used for inhabitants of the home to talk to guests at the door "when it isn't convenient to come to the door yourself" (85). The low-pitch roof of the home is clad in aluminum panels as a durable and lightweight solution.

Landscaping in this home was given as much attention as the architectural elements of the home. Landscape architect Garrett Eckbo designed the outdoor plan "to enhance the exterior livability and efficiency of three main parts of the house: the entry garden, with driveway and turnabout parking space; the service yard close to kitchen and laundry, where less attractive household activities, like clothes-drying and trash removal, can go on against the planned greenery of small, raised

Figure 30: Birds-eye Rendering of home and landscaping plan detailing out the innovative indoor/outdoor spaces and coutyards. House Beautiful, May 1946, Pg. 88 flower beds; and the garden patio, a 60 sq. ft. of outdoor living space, where the family could relax, play, entertain, or do their barbecue dining in snug privacy afforded by three sides of the house and the garden fence" (House Beautiful, 1946, 88). The success of the outdoor

design is due to the continued work with architects and designers to blend the two spaces. Because the designers hope to promote a duplicity of living space and they view the patio as only a "continuation of the indoor living room separated from it only by a clear glass wall.... Colors and textures of its planting and masonry have been chosen to blend with the living room decoration" (88). With the inclusion of a holistic landscaping 
plan, the entirety of the property is designed and integrated into a post-war home that attempted to reinvent our concept of what a home could offer to its owner.

Ultimately, the "First Postwar House" cements its place in this review in part due to its interesting use of unusual advertisement and the role this particular housing forum played in propagating the American Dream. Building off of the continued aspirations the Dream and American prosperity, the prototypical home was celebrated not for their use as a vehicle to achieve the Dream (as many other developers has done) but rather as an outlet for ideas and products to "IMPROVE your dream" (84). As the article explains, "inside and outside of this completed postwar house, you will find more ideas, more excitement, than in all your wartime dream houses... you may not want all these ideas but they are the stuff that better dreams are made of" (84).

Moreover, the "First Postwar House" is important as an evaluation of the postwar housing market because of its representation of experimentation through new products and technologies in an era to which a lot of excitement existed about possibilities that new-age housing could bring. While the home was not built as a model home to be replicated in row after row of suburban streets, what the designers and developer were able to create was a real example of how meaning could be brought into the suburban landscape. In fact, the project itself is hailed in its honesty; the article exuberantly states: "the MEANING of this plan is more important than the plan itself" (House Beautiful, 1946, 86). By bringing better, user oriented design solutions to the average homeowner, the integration of the best solutions that design professionals could provide in the modern American home. 
Ultimately, the inclusion of modern and/or futuristic home designs in the housing market was a slow process. Rather than witness a dramatic change in housing design, bits and pieces of prototypical homes would be introduced into traditional designs in the evolution of residential design. Such a slow transition occurred in part due to fashion preferences and worries over resale and marketability over a style that was perhaps less "proven" than more traditional variations. Moreover, there also existed a lower amount of risk willing to be taken on the part of the homeowner because of the mentality given towards home purchases during the postwar era. Most homeowners saw this as a life purchase, rather than a rung on the property ladder, and choosing a more traditional style was seen as safer and timeless than compared to its more modern counterparts. In an editorial reprinted in John E. McNamara's "How to get the most house for your money" by associate editor of Better Homes and Gardens Magazine John Normile, this topic of finding a balance between the "best of the extreme and the finest of traditional. He states:

"To announce that our postwar homes will be push-button palaces of metal and glass and plastic would be as foolish as to call the Cape Cod cottage the last word in home design. Either statement would be as full of holes as a Swiss cheese. The truth probably lies somewhere between. We believe that the average family has basically good taste and is eager to accept sensible innovations in home design. We know them, however, to be essentially conservative when buying a home, largely because this is the greatest single investment any one family ever makes. Their viewpoint on homes designs is not the same as it is in the selection of an automobile, refrigerator, or other 
appliances, where the sum spent is much smaller an involves less future risk. Again, sentiment and tradition are strong in home building. Both are encouraged by builders, most of whom tend to resist change.... Besides convincing the home owner of the soundless and practical value of the ideas [Better Homes and Gardens] present to him, we must choose a bit of both the best extreme and the finest traditional designs. To lean too far toward the new would shock the prospective builder - and to lean too far backward would equally discourage him." $(1948,133)$.

Finding a balance between forward thinking design and traditional taste was clearly an act that not only homeowners had to traverse, but magazines and designers as well. Prototypical house designs afforded the experimentation to step forward, even if it was only a baby step.

\section{Aspirations \& Renovations:}

Figure 32: Existing Craftsman Bungalow renovated to enclose the front porch and make it updated to post-war standards. Better Homes \& Gardens Magazine.

December 1948, Pg. 51.

Decentret 1 गTण, 1 g. J1.
While much of the visual culture in the post-war era emphasized new construction, Levittown start-ups, and new-family financing, there was also a great amount of information and design renovations of existing structures. "Undesirable" housing styles such as Spanish, Craftsman, or Victorian homes were given over-hauls to meet the new Cape-Cod and Ranch vogue. When examining the "recommendations" of housing authorities for renovating these structures, a great deal can be learned about the preferences of the majority and the various factors that influenced design.

To begin, front porches, was the major casualty when regarding the transformation from one style into the Cape Cod or the Ranch. During this particular 
era, the porch was seen as wasted space. For example, in such a case as this December 1948 Better Homes and Gardens article "Save Your House from Middle-Age", design professionals regard an existing front porch as "the sort our generation swung and necked on, darkened the living room, and made it best for melancholy brooding". Their suggestion, as seen in Figures 31 and 32, was to enclose the space in, add a picture window and increase interior space. Any sort of flexible interior/exterior space that would be considered at least semi-similar to the porch would have been in the inclusion of a breezeway or side porch leading from the home to the detached garage or carport. Otherwise, the front porch was seen as too dominant and heavy over the exterior and did not lead to a light filled interior. Breezeways and screened in porches located on the side of the home was considered a much more desirable exterior trait.

Figure 33: Kramer Residence in Highland Park, Illinois before the post-war renovation. Better Homes and Gardens, July 1947, Pg. 49
In regards to exterior finish choices, a very interesting trend began to occur. On face value the choice of many new construction homes would seem as if their preference only on keeping costs low with the use of clapboard and aluminum siding. However, when looking at suggestions from various home design magazines it becomes evident that these cost saving measures actually became a vogue item over more durable and expensive options in terms of new construction. In the case of renovations, the look of light exterior and clean lines were a valued design feature of this era and is often seen when looking at suggestions given by professionals and testimonials of homeowners. Often homeowners were instructed to paint over red brick with whitewash and recover eaves and gables with white clapboard to make the appearance seem clean and light. 
In one example, homeowners Julian Kramer and his wife purchased an "ugly" older brick home on Sheridan Road in Highland Park, IL and proceeded to renovate it to late 40's vogue standards, as documented in the July 1947 Issue of Better Homes and Gardens Magazine. As journalist Marion Winter states in regards to the existing state of the home: "The entrance arrangement was bad and the old-fashioned sun porch was worse. The screened porch, which they considered essential, wasn't there at all... The

Figure 34: Kramer Residence after the renovation showing the new white exterior and picture window, among other changes. Better Homes and Gardens, July 1947, Pg. 49 exterior [renovation] is really a testimonial to the power of paint - white on bricks..." $(1947,49)$. As seen in the accompanying images to the left, the changes to this home seem to fit many of the same characteristics of new construction and are telling of era specific design changes that make these post-war homes different from previous styles.

In another example of post-war residential renovation, David A.

Figure 36:

Hayes Oak Park Home after renovations. Their previous bungalow was transformed in to a Cape Cod style home. Better Homes and Gardens Magazine, July 1947, Pg. 53 
Much like the previous renovation, this gives specific clues to era specific design preferences and allows for clearer lines to be drawn between previous housing trends and those that evolved out of the post-war housing boom.

\section{Surveying Suburbia \& D.I.Y. Decor:}

While the house designs described above have been constructed in numbers that would indicate overwhelming popularity, looking at sheer numbers alone only provides a kind of circumstantial evidence towards their fulfilling of the homeowners needs and wants. As discussed previously, period magazines not only acted as a showcase for popular housing designs, but also as a forum for discussion between architects, designers, builders, and the homeowners themselves. One such means by which these venues gathered such information was through surveys conducted to poll their readers.

While there are a great amount of information and topics covered through various surveys conducted by each magazine, there are quite a few that stand out in particular in their ability to discern the true needs and wants of the post-war homeowner and how the previous home styles discussed respond to them. While their findings in some respects are quite abstruse due to the nature of polling being voluntary (mail in responses and interviews) and including such a large scope of participants (all of their magazine consumers of any age, income level, and years of homeownership), the amount of information they were able to gather is quite detailed and reflects quite a bit 
of complexity and contradiction in the shifting residential landscape of the average American homeowner.

In a survey done in 1955 by Better Homes and Gardens Magazine revealed that the reasons behind the home purchases of many peacetime families since the war concluded was out of more pragmatic centric nature. Not unlike homebuyers of today, most homebuyers had to compromise between budget and location. While the wants of most homeowners included privacy, larger lots, and a desire for increased space; the reality was that most lots purchased were an average of 11,100 square feet and homes were an average of 983 square feet [a decrease of 12 percent from the average size in 1940] (Better Homes and Gardens, 1955, The New House, 10; as quoted in Clark, 1986, 228). While smaller houses allowed many Americans to purchase a single family home, such residents weren't necessarily without the desire of more space and room for privacy.

In contradiction to this study, however, it was found that despite the fact that the participants in the Better Homes and Gardens survey said that they were unsatisfied with the size of their homes, the overwhelming single factor that drove homeowners to move to suburbia, in the editors opinion, was because it allowed an escape from the cramped urban core. In fact, the editors of Better Homes and Gardens magazine imply that the most important factor "pushing people to the suburbs is the desire of families for elbowroom - the desire to get away from it all, where life is more informal, where there is plenty of yard room for the children, and where they can enjoy a maximum of 
outdoor living" (Better Homes and Gardens, "The New House", pp. 8; As quoted in Clark 1986, 231).

While it is largely accepted that the suburban homes were a general improvement from the apartment inner-city living quarters, they were not without flaw. The homes were stand-alone, single family residences but were still significantly smaller than similar residences built in the previous decade. Outdoor space was abundant, yet interior space left something to be desired. Compromise and prioritizing of needs were paramount to enter into the suburban neighborhoods, and magazine publications discuss and reflect the inner turmoil of home building.

Much like today, Do-It-Yourself (DIY) projects were common and featured commonly in various volumes. In fact, in the following years, the average size of the suburban home grew not because of demand on home builders, but through do-ityourself projects by the homeowners themselves. By 1955, when Better Homes and Gardens conducted an additional survey to follow up with their findings, "the number of homes being built with six or more rooms had increased by 6 percent and more than half of all new houses had three bedrooms...substantial numbers of families were now willing to trade of a separate dining room for a combination living-dining room and kitchen eating area... [and] the floor area for houses costing $\$ 10,000$ had increased from 983 square feet to $1,100 "$ (Clark, 1986, 230). Although inflation of building costs did exist, the reasons for the stark increase was due to the fact that "62 percent of all home buyers now did some of the construction work themselves....[and] a surprising 23 percent did all or almost all of the work themselves" $(1986,231)$. 
In an additional survey done by the Housing and Home Finance Agency titled "What People Want" found that "70 percent of new home buyers held back enough money to make some improvements as soon as they moved in" (as quoted in Clark, $1986,230)$. While some of these improvements were included as an outlet to personalize their home, the same study also found that DIY projects were one of the founding reasons for the success of suburbia all together. While many suburban homes themselves were seen to the public eye as being void of any uniqueness or individualism, DIY projects were seen as the method to which the homeowner could regain a sense of self and personalization in their private space.

\section{The Significance of Suburbia:}

\section{Setting the Precedence for Picturesque.}

While the glossy pages of American magazines paint a picturesque home-scape of suburbia, the glamorization of house and home also reflects a reality riddled with high expectations and unbridled excitement for where the post-war prosperity was heading. While suburbia was not a new phenomenon, the post-WW2 era left its population motivated and hopeful for what the future could, and would, hold in store for them. Magazines were an integral part in forming the residential manifestation of this mentality. While on one hand home and culture magazines are a piece of visual culture that reflects a sense of "idealism", their ability to influence, project, and connect with the suburbia of everyday is integral to our understanding of how suburbia was created. 
Understanding the importance of how we use our media outlets and instruments to both promote and understand our housing trends is critical to examining the pieces of our culture that impact our choices. While magazines are almost never impartial, their relentless goal of influencing and reflecting residential design allows them to become a source of what the masses desire for themselves and their homes; a fact that remains as true today as it did in the post war era. While design and home specific magazines focus largely on the physical manifestation of our public and private needs of our most personal space, the importance of the home as a piece of our own visual culture reaches far beyond plans, sections and elevations. The organization, design, and symbolism we associate with specific house designs and home settings represent a larger socio-cultural movement occurring. Much like the quote by archaeologist Nancy Stahl which began this review, it has been my motive to implore others to regard suburban home design not just as a piece of overly-replicated banal construction, but as a piece of architecture that was constructed out of specific events in our history and reacted to important social and cultural shifts.

The late 1940's and early 1950's offered housing options that reacted to the return of the Gl's and the national manufacturing production rates. Specifically geared towards new homeowners looking to take an exodus from the urban tenements and those looking to achieve a familial atmosphere for their children, suburban housing in the postwar era was often advertised and examined in magazines the cost to benefit of a suburban home and family life. The popular ranch style, as discussed previously, evoked imagery of a kind of "rambling" abode even though most ranch-style houses of 
the 1950's had less square-footage than the average house from 30 years prior (Wright 1981, 251). There was something symbolically appealing about the low-pitched roof, heavy eaves, long lines, and horizontal nature of its form. Practically speaking, the lack of stairs, open interior space and view of the backyard continued to aid in its functionality and place as one of the most supreme housing types suitable for family life. In fact, the ranch house was one of the few housing styles chosen to be a part of a short series of model homes promoted by Parents' Magazine, cementing the connection between a housing style and the importance of creating a safe, supportive and successful family atmosphere. In an excerpt by Parents' Magazine reproduced in John E. McNamara's "How to get the most house for your money" (1948), family home editor Maxine Livingston states:

"As everyone knows families with children represent by far the largest market of homes. Yet, why is it that builders too often overlook the important problem of planning the house of family relationships? Why are they so concerned with the style of the house when their efforts should be concerned with planning houses - even the smallest houses - that are efficient, comfortable to live in, and suitable for children to grow in." $(1948,143)$

However, the ranch was not the only standout of this suburban boom. The Cape Cod was the primary housing form chosen by Levitt \& Sons Co. as they began their infamous track housing communities not just because of their efficiency to construction, but perhaps more importantly, because of its strong traditional ties to memory and history of family and meaning. Strengthened by intense media coverage, the Levitt Cape 
Cod became a symbol of a era and continued to influence the way other builders approached home construction. As Fortune magazine reported in 1952, "a few years after each new model appeared, Levitt's built-in features became commonplace.... Across the country, radiant heated concrete slabs replaced basements, double-glazed sliding windows and doors in a light, aluminum frame opened onto patios, carports...could be found in thousands of developers' houses" (as quoted in Wright 1981, 253). The Cape Cod, in many respects, was a catalyst for significant architectural and construction changes in American residential housing.

However, these changes were not just indicative of a flash-in-the-pan style trend or builder's desires to cut cost, but rather a barometer for larger social indicators as well. Surveys, whether done by the federal government, popular magazines and social scientists, was a popular method of endorsing new housing styles and suburban communities and strengthening the bond between suburban life and family atmosphere. According to Wright (1981), "social scientists studied the 'average family' in the suburbs, and psychologists published 'livability studies' that correlated the domestic environment with statistics on crime and family stability" (Wight, 1981, 253). The results of such studies resulted in a new, more methodical approach to how merchant-builders gain success and aided in the "responsible" decisions in home purchasing and family building. Ultimately, Wright (1981) explains that the end result of these studies and extensive research was to reinforce the feasibility of the "American Dream". As she rationalizes further, stating, "young couples who moved out to the suburbs hoped to find the 'dream house' and the 'dream life' they had thought about so 
often during the war...[and] with extensive research about the most prevalent domestic fantasies, builders tried to provide what the majority of surveyed families wanted" (253). In many regards, the fantasy life that homeowners wanted and builders attempted to create, often revolved around an expectation of a fantasy lifestyle as well. Family centric design that coincided with social expectations of gender roles and child rearing was also the focus of many "prototype houses" propagated in domestic magazines and guides at the time. While fixtures and finishes were often of a higher quality than what would have been found in the average suburban home, there was an air of experimentation and excitement over the perceived ability of house design

Figure 37:

First Prize winning ranch home design predicated upon family life and recreational areas within the home for child rearing and entertaining. Judged by the editors of Good Housekeeping and former editor of American Builder Magazine.

McNamara, J.E. (1948). "How to get the most house for your money". Chicago. 112. positively influencing marriage relationships and child rearing. Women

Today (1953) advised the attentive wife to give her husband a space apart from the children, while Parents' Magazine (1947) advocated for the increased inclusion of a multipurpose or family room into home design to attend to children's needs (Wright, 1981, 255). Suburban houses acted, at least symbolically, as a kind of haven for family values and were often advertised to the masses as a way of encompassing traditional family values, safety, and stability into a physical form.

However, what is ultimately important to understand is that "suburbia has never been a haven from social issues; rather, suburbia has been shaped by them" (Baxandall \& Ewen, 2000, 260). Fundamentally speaking, we refer to our houses as "homes" because there exists a psychological need to create private place from space, kindle our 
most personal relationships, and attach ourselves to our community and culture. In many ways, these same reasons are why we also identify a home as an integral piece of achieving the "American Dream". Because of this, it would be ultimately naive to exclude the American suburbs from being devoid of any sort of meaningful indicators of cultural or social significance.

What magazines and period media afford us is the ability to look at both how suburbia was perceived and projected, but also a way of examining the primary literature suburbanites would have used to design and select their own home. Postwar suburban homes, and the magazines to which they were included within, hold a great deal of merit and value as a piece of American history and visual culture. While there will be an amount of utopian ambivalence and perfectionist persona when we regard magazines, the same sentiment exists towards the "American Dream" as well. The American consumerist culture lends itself inherently reliant on published materials and advertisements to influence an emerging national housing aesthetic. The ability for information sharing across the globe, let alone across the United States, ushers in an increasingly shared national housing aesthetic, allowing for nationally issued publishing to play a strong role in shaping trends and distributing house designs.

Moreover, the physical manifestation of a "home" holds a strong hold over how we evaluate our personal success in establishing our own American dream. In many ways, our homes become a reflection of self, family, culture and society at large. By taking a look at postwar suburban house design as a product of those factors, we allow the suburban house to become an object that holds immense symbolism and 
information as a modern artifact. Such an artifact could hold important meaning and influence in other fields of inquiry as well.

Implications of this research could expand to social sciences and further environment and behavior research into how the built environment is continually influenced by socio-cultural factors. Moreover, it can be subsequently researched into both factors as being a part of a symbiotic relationship. For example, examining how the built environment influences user behavior and societal expectations for inter-personal relationships and expectations for gender roles may also be investigated further.

Additional research may be conducted into other housing styles and architectural trends as they pertain to the decade in question. Moreover, inquiry into more finite detail of housing variants within a particular style could be done additionally to provide more depth to those housing styles already included in the study. Other forms of media influence may also be included, discussing how television, movies, newspaper advertisements and government issued propaganda are some forms suggested for additional research.

Ultimately, the significance of studying post-war American suburban design is greater knowledge of the history of our most personal spaces and places. Understanding the multi-dimensional factors that influence why we build and how we built has ramifications for research on residential housing trends through present day. While the methods of this research have been primarily archival, the same research could be conducted on newly published materials for examination of new construction communities. 
References:

Altman, I., \& Chemers, M. (1980). Culture and environment. New York: Cambridge University Press.

Archer J. (2005). Architecture and suburbia: From english villa to american dream house, 1690-2000. University of minnesota press. Xv.

Baxandall, R. \& Ewen, E. (2000). Picture windows: How the suburbs happened. New York: Basic Books.

Berger, P. L., \& Luckmann, T. (1966). The social construction of reality: A triste on the sociology of knowledge. (p. 51). Garden City, New York: Anchor Books.

Brown, R., \& Maulin, D. (2012). Concepts of vernacular architecture. IN C. Crysler, S. Cairns \& H. Heynen (Eds.), The SAGE handbook of architectural theory (pp. 340-355). London: SAGE Publications Inc.

Beauregard, R.A. (2006). When American became suburban. University of Minnesota. ix, $x$,

Clark, C.E. (1986). The american family home: 1800-1960. University of North Carolina Press. 193-204

Clark, W. A. V., Deurloo, M. C., \& Dieleman, F. M. (1984). Housing consumption and residential mobility. Annals of the association of american geographers, 74(1), 29-43. Retrieved from www.jstor.org/stable/2562611

Cullen, J. (2003). The american dream: a short history of an idea that shaped a nation. Oxford. 136.

Curran, S. R., \& DeSherbinin, A. (2004). Completing the picture: The challenges of bringing "consumption" into the population-environment equation. Population and environment, 26(2), 107-131. Retrieved from http://www.jstor.org/stable/27503912

Ellaway, A., McKay, L., Macintyre, S., Kearns, A., \& Hiscock, R. (2004). Are social comparisons of homes and cars related to psychosocial health?. International Journal of Epidemiology, 33(5), 1065-1071. Retrieved from 
http://ije.oxfordjournals.org/content/33/5/1065.full.pdf html

Glassie, H. (1999). Material culture. Bloomington: Indiana University Press. 413.

Graeber, D. (2011). Consumption. Current anthropology, 52(4), 489-511.

Groat, L. \& Wang, D. (2013) Architectural Research Methods, Second Ed. Wiley. 173214.

Better Homes and Gardens Magazine. (1950-present). Meredith Corporation. Print

Heller, A., \& Adams, T. (2009). Creating healthy cities through socially sustainable placemaking. Australian Planner, 46(2), 18-21. doi

Hudson, L.B. (1984). Modern material culture studies anthropology as archaeology: Normative functions of material culture the emic basis of material culture. The American Behavioral Scentist. 28(1), 31.

Hunter C. (1999). Ranches, rowhouses and railroad flats. New York .166.

Jackson, P. (2004). Local consumption cultures in a globalizing world. Transactions of the institute of british geographers, 29(2), 165-178. Retrieved from http://www.jstor.org/stable/3804552

Kluckhohn, C. (1949). Mirror for man: the relation of anthropology to modern life. University of Arizona Press. Print.

Ksee, C. K., Yang, Y., Li, N., \& Shen, L. (2009). Wealth, warmth, and well-being: Whether happiness is relative or absolute depends on whether it is about money, acquisition or consumption. Journal of marketing research, 46(3), 396-409. Retrieved from http://www.jstor.org/stable/20618900

Lees-Maffei, G. (2009). The production - consumption - meditation paradigm. Journal of Design History, 22(4), 351-376.

Marling, K.A. (1996). As seen on tv: The visual culture of everyday life in the 1950's. Cambridge: Harvard University Press. 
McCracken, G. (1988), Culture and Consumption: New Approaches to the Symbolic Character of Consumer Goods and Activities, Bloomington: Indiana University Press.

Meyer, B. D., \& Sullivan, J. X. (2003). Measuring ther well-being of the poor using income and consumption. The journal of human resources, 38, 1180-1220. Retrieved from http://www.jstor.org/stable/3558985

Miller, D (1987). Material culture and mass consumption. Basil Blackwell, Oxford, 240.

Moskowitz, M. (2004). The standard of living: The measure of the middle class in modern America. Baltimore: Johns Hopkins.

Prown, J.D. \& Haltman, K. (2000). American artifcacts: Essays in material culture. East Lansing: Michigan State University Press.

Pompilio, N. (2014). Legends and Legacies: William Levitt: Father of Suburbia. Online. http://www.legacy.com/news/legends-and-legacies/william-levitt-father-ofsuburbia/1944/

Rapoport, A. (1995, 2005). A critical view of the concept of "home".

Rathje, W.L. (1979). Advances in archaeological method and theory. Springer. Vol. 2. 137.

Rosenbaum, R. (1983, December 1). The House that Levitt Built. Esquire, pp. 378-391.

Rotenberg, R. (2001). Metropolitanism and the transformation of urban space in nineteenth-century colonial metropoles. American anthropologist, 103(1), 7-15.

Stahl, N. (1975). Jelly side down: Questions soon beyond a mother. Universal Press Syndicate.

Schaefer \& Lamm, (1995). Sociology. (Ch. 5.).

Schoenauer, N. (2000). Six thousand years of housing. APT Bulletin. 413-420.

The industrialized house: The greatest house building show on earth. (1947, March). Architectural Forum, 105. 
The six thousand houses that levitt built. (1948, January 1). Harper's Bazaar Magazine, pp. 79-83.

Up from the potato fields. (1950, July 3). Time, p. 53.

Vikko, A. (1996). The home as a meaning-making factor in autobiographies written by elderly men and women. The $13^{\text {th }}$ Scandinavian gerontology conference.

Wajda, S. \& Sheumaker, H. (2007). Material culture in america: understanding everyday life. ACB-CLIO.

Wright, G. (1981). Building the dream: A social history of housing in america. Cambridge: MIT press. 246-416. 